\title{
CORRECTION
}

\section{Correction: Public interest in dietary supplements for prostate cancer prevention}

Devin N. Patel, Paige Kuhlmann, Pao-Hwa Lin and Stephen J. Freedland

(c) The Author(s), under exclusive licence to Springer Nature Limited 2021

Prostate Cancer and Prostatic Diseases (2022) 25:376; https://doi.org/10.1038/s41391-021-00410-8

Correction to: Prostate Cancer and Prostatic Diseases https://doi. org/10.1038/s41391-020-0257-8
In the original version of this article unfortunately contained a mistake. The spelling of Stephen J. Freedland name was incorrect. The original article has been corrected. 